\title{
Increase in the Pool Size of Releasable Synaptic Vesicles by the Activation of Protein Kinase C in Goldfish Retinal Bipolar Cells
}

\author{
Ken Berglund, Mitsuharu Midorikawa, and Masao Tachibana \\ Department of Psychology, Graduate School of Humanities and Sociology, The University of Tokyo, \\ Tokyo 113-0033, Japan
}

\begin{abstract}
Secretion from neurons and neuroendocrine cells is enhanced by the activation of protein kinase $\mathrm{C}(\mathrm{PKC})$ in various preparations. We have already reported that transmitter (glutamate) release from $\mathrm{Mb1}$ bipolar cells in the goldfish retina is potentiated by the activation of PKC. However, it is not yet settled whether the potentiation is ascribed to the increase in the pool size of releasable synaptic vesicles or in release probability. In the present study, $\mathrm{Ca}^{2+}$ influx and exocytosis were simultaneously monitored by measuring the presynaptic $\mathrm{Ca}^{2+}$ current and membrane capacitance changes, respectively, in a terminal detached from the bipolar cell. The double pulse protocol was used to estimate separately the changes in the pool size and release probability. The activation of PKC by phorbol 12myristate 13-acetate (PMA) specifically increased the pool size
\end{abstract}

but not the release probability. PKC was activated by PMA even after the $\mathrm{Ca}^{2+}$ influx was blocked by $\mathrm{Co}^{2+}$. In bipolar cells the releasable pool can be divided into two components: one is small and rapidly exhausted, and the other is large and slowly exocytosed. To identify which component is responsible for the increase in the pool size, the effects of PMA and a PKC-specific inhibitor, bisindolylmaleimide I (BIS), on each component were examined. The slow component was selectively increased by PMA and reduced by BIS. Thus, we conclude that the activation of $\mathrm{PKC}$ in $\mathrm{Mb} 1$ bipolar cells potentiates glutamate release by increasing the pool size of the slow component.

Key words: protein kinase C; releasable synaptic vesicle; release probability; membrane capacitance measurements; retinal bipolar cell; exocytosis; endocytosis
The activation of PKC potentiates secretion in a variety of neurons (Yawo, 1999; Oleskevich and Walmsley, 2000) and neuroendocrine cells (Gillis et al., 1996; Cochilla et al., 2000). The potentiation is ascribed to the modulation of exocytotic machinery (Hori et al., 1999), although in some preparations changes in $\mathrm{K}^{+}$or $\mathrm{Ca}^{2+}$ channels (Bowlby and Levitan, 1995; Stea et al., 1995; Hoffman and Johnston, 1998) may indirectly increase the secretion. The modulation of exocytosis downstream of the $\mathrm{Ca}^{2+}$ influx could be explained by two distinct mechanisms: an increase in the $\mathrm{Ca}^{2+}$ sensitivity of exocytosis (possibly release probability) and an increase in the amount of releasable synaptic vesicles (the pool size). The former is supported by the shift in the relationship between the external $\mathrm{Ca}^{2+}$ concentration $\left(\left[\mathrm{Ca}^{2+}\right]_{\mathrm{o}}\right.$ ) (or the amount of the $\mathrm{Ca}^{2+}$ influx) and the transmitter release after the activation of PKC (Yawo, 1999; Oleskevich and Walmsley, 2000; $\mathrm{Wu}$ and $\mathrm{Wu}, 2001)$. On the other hand, the latter is supported by the phorbol ester-induced fourfold increase in the amount of exocytosis, which is evoked by the depolarizing pulse that is strong enough to exhaust the readily releasable pool before the application of the agent (Gillis et al., 1996).

Retinal bipolar cells are the second-order neurons, receiving

\footnotetext{
Received Dec. 6, 2001; revised March 29, 2002; accepted April 3, 2002.

This work was supported by Grants-in Aid for Scientific Research (12053212) and the Special Coordination Funds for Promoting Science and Technology (the Project on Neuroinformatics Research in Vision) from the Ministry of Education, Science, Sports and Culture, and from the Japan Society for the Promotion of Science (11480245) to M.T. We thank Tomoyuki Takahashi for discussion and comments on this manuscript and Naotoshi Minami for participation in early experiments. K. Berglund is a research fellow of the Japan Society for the Promotion of Science.

Correspondence should be addressed to Masao Tachibana, Department of Psychology, Graduate School of Humanities and Sociology, The University of Tokyo, 7-3-1 Hongo, Bunkyo-ku, Tokyo 113-0033, Japan. E-mail: Ltmasao@L. u-tokyo.ac.jp.

Copyright (C) 2002 Society for Neuroscience $0270-6474 / 02 / 224776-10 \$ 15.00 / 0$
}

inputs from rods and/or cones and feeding outputs to ganglion and/or amacrine cells. PKC is ubiquitously found in rod bipolar cells of various species (Negishi et al., 1988). It has been suggested that PKC of bipolar cells regulates GABA sensitivity (Feigenspan and Bormann, 1994; Gillette and Dacheux, 1996) and induces morphological changes in axon terminals (Job and Lagnado, 1998).

In the goldfish retina, Mb1 bipolar cells are immunolabeled by antibodies against PKC $\alpha$ (Suzuki and Kaneko, 1990) and PKCe (Osborne et al., 1994). Other subtypes of PKC ( $\beta$ and $\gamma$, Suzuki and Kaneko, 1990; $\delta$ and $\zeta$, Osborne et al., 1994; $\theta$ and $\lambda$, McCord et al., 1996) are not detected in bipolar cells of the goldfish retina. It has been reported that $\mathrm{PKC} \alpha$ is activated by $\mathrm{Ca}^{2+}$ and diacylglycerol, whereas PKC $\epsilon$ does not require $\mathrm{Ca}^{2+}$ for its activation (for review, see Asaoka et al., 1992).

The large size of the axon terminals of Mb1 bipolar cells enabled us to examine the mechanisms of transmitter release (for review, see Tachibana, 1999; von Gersdorff and Matthews, 1999). We have already shown that the activation of PKC potentiates transmitter release from $\mathrm{Mb} 1$ bipolar cells through the action downstream of the $\mathrm{Ca}^{2+}$ influx (Minami et al., 1998). However, it is not yet solved whether the potentiation is ascribed to changes in the pool size of releasable synaptic vesicles or in release probability. In the present study, we used a quantitative approach to distinguish between two possibilities and concluded that the activation of PKC increases the pool size of releasable synaptic vesicles. The increase was mostly restricted to the slow component of exocytosis, and the fast, more easily exhaustible component was little affected. Endocytosis did not change obviously after the activation of PKC.

\section{MATERIALS AND METHODS}

Cell isolation. The terminals of Mb1 bipolar cells were obtained from the goldfish (Carassius auratus) retina as previously described (Tachibana 
A $3.5 \mathrm{Ca}$
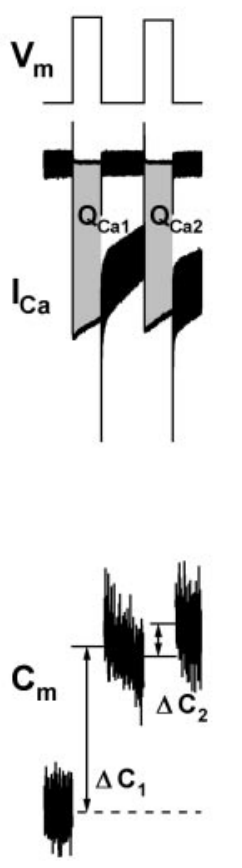

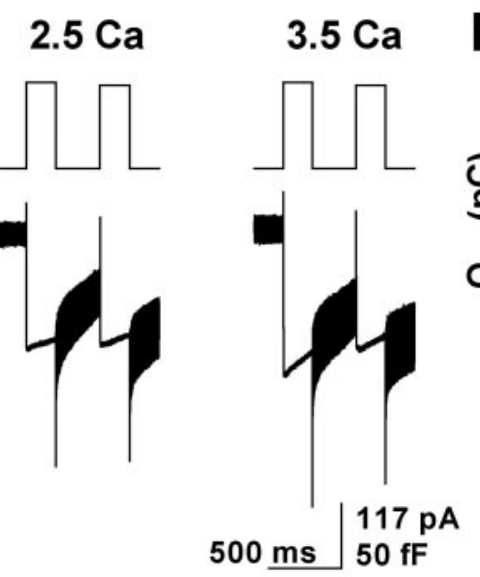

B a
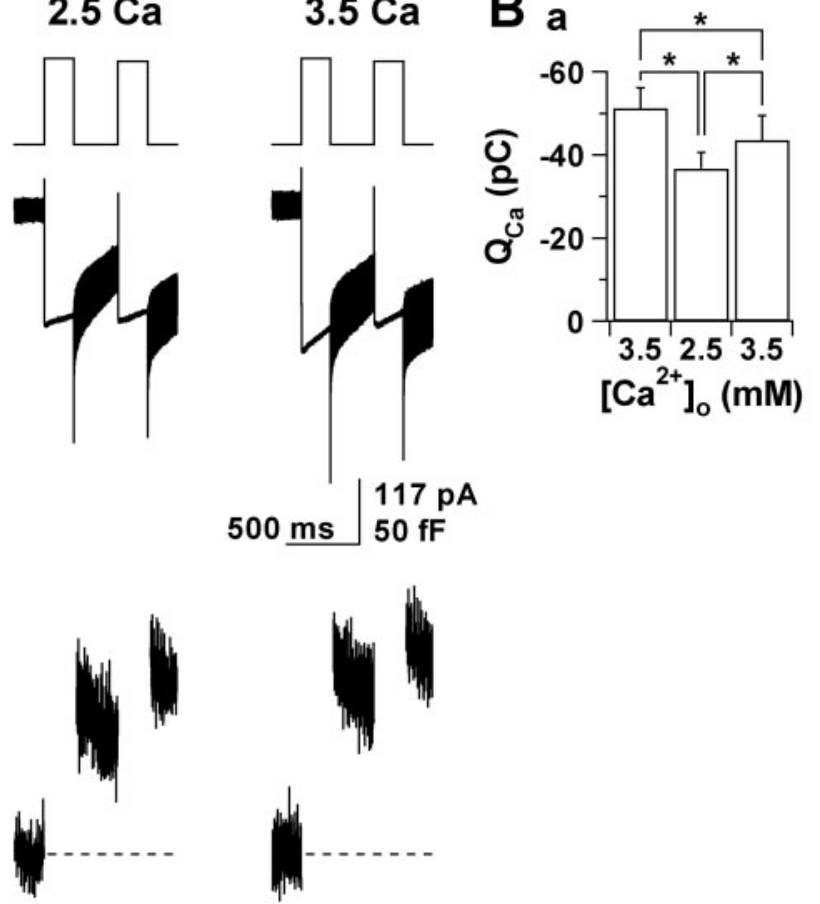

b

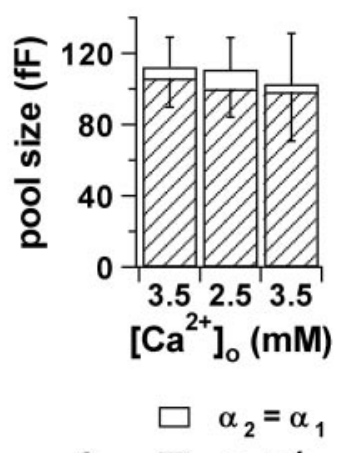

c $\alpha_{2}=1$

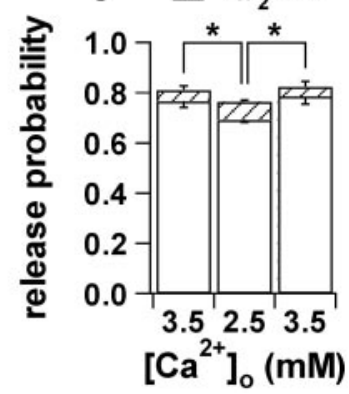

Figure 1. Estimation of the pool size and release probability by the double-pulse protocol. Changes in $\left[\mathrm{Ca}^{2+}\right]_{\mathrm{o}}$ affected release probability but not the pool size. $A$, The double-pulse protocol. Two $200 \mathrm{msec}$ pulses were applied with an interpulse interval of $300 \mathrm{msec}$ to a terminal detached from the Mb1 bipolar cell. The intensity of the second pulse (to $-2 \mathrm{mV}$ ) was adjusted to produce a similar $\mathrm{Ca}^{2+}$ current $\left(I_{\mathrm{Ca}}\right)$ evoked by the first pulse (to $0 \mathrm{mV}$ ). The thick parts in $I_{\mathrm{Ca}}$ were evoked by a $1 \mathrm{kHz}$ sine wave superimposed on the holding potential of $-60 \mathrm{mV}$ to calculate the membrane capacitance $\left(C_{\mathrm{m}}\right)$. In this figure the sine wave was omitted from the trace of the membrane potential $\left(V_{\mathrm{m}}\right)$ for clarity. The pool size and release probability were estimated based on two capacitance jumps $\left(\Delta C_{1}\right.$ and $\Delta C_{2}$, see Materials and Methods). $I_{\mathrm{Ca}}$ was integrated to calculate the amount of $\mathrm{Ca}{ }^{2+}$ influx during depolarization $\left(Q_{\mathrm{Ca} 1}\right.$ and $\mathrm{Q}_{\mathrm{Ca} 2}$; shadow regions in $\left.I_{\mathrm{Ca}}\right)$ after subtraction of the leak current, which was obtained in the Co ${ }^{2+}$ solution (nearly flat trace in $\left.I_{\mathrm{Ca}}\right)$. The double pulses were repetitively applied every $40 \mathrm{sec}$ in two different $\left[\mathrm{Ca}^{2+}\right]_{\mathrm{o}}(3.5$ and $2.5 \mathrm{mM})$. The illustrated data were obtained within 3 min after rupture of the patch membrane. $B$, Effects of $\left[\mathrm{Ca}^{2+}\right]_{\mathrm{o}}$ on $Q_{\mathrm{Ca}}(a)$, the pool size $(b)$, and release probability $(c)$. Data were obtained from four terminals. Open and shaded bars $(b, c)$ are obtained on the assumption that the release probability after the first pulse remains constant $(\alpha 2=\alpha 1)$ and increases to 1, respectively (see Materials and Methods). Asterisks denote significant difference in the two-tailed, paired Student's $t$ test $(p<0.05)$. Error bars in this and the subsequent figures denote SEM.

and Okada, 1991). In brief, a goldfish (body length, 15-20 cm) was killed by decapitation followed by immediate pithing of the brain and spinal cord, in accordance with The Manual for the Conduct of Animal Experiments in The University of Tokyo and Guiding Principles for the Care and Use of Animals in the Field of Physiological Sciences, The Physiological Society of Japan. Retinas were detached from the pigment epithelium of the enucleated eyes. The isolated retinas were treated with hyaluronidase $(0.1 \mathrm{mg} / \mathrm{ml})$ for $5 \mathrm{~min}$ and then with cysteine $(5 \mathrm{~mm})$-activated papain $(1.25-2 \mathrm{mg} / \mathrm{ml})$ for $15-20 \mathrm{~min}$ at $28^{\circ} \mathrm{C}$. These agents were dissolved in a $\mathrm{Ca}^{2+}$-free solution, which consisted of (in $\mathrm{mm}$ ): $\mathrm{NaCl}, 110 ; \mathrm{KCl}, 2.6$; $\mathrm{NaHCO}_{3}, 1 ; \mathrm{NaH}_{2} \mathrm{PO}_{4}, 0.5$; sodium pyruvate, 1 ; HEPES, 4; and glucose, $16, \mathrm{pH} 7.2,260 \mathrm{mOsm}$. The retinas were then mechanically triturated with a glass pipette. A few drops of cell suspension were plated on a culture dish (Falcon 3001; Becton Dickinson, Franklin Lakes, NJ). Isolated cells were allowed to settle on the bottom of the dish for $15 \mathrm{~min}$ and were then superfused continuously with a control solution at a rate of $0.3-0.5 \mathrm{ml} / \mathrm{min}$. The axon terminals detached from Mb1 bipolar cells were identified by the size $(\sim 10 \mu \mathrm{m}$ in diameter), the bulbous shape (often with a short axon stump), and the sustained inward current (the L-type $\mathrm{Ca}^{2+}$ current; $I_{\mathrm{Ca}}$ ) evoked by a depolarizing pulse (Tachibana et al., 1993). Recordings were performed at room temperature $\left(\sim 23^{\circ} \mathrm{C}\right)$ within $2 \mathrm{hr}$ after dissociation.

Superfusate. The control solution contained (in $\mathrm{mm}$ ): $\mathrm{NaCl}, 125 ; \mathrm{KCl}$, 2.6; $\mathrm{CaCl}_{2}, 2.5 ; \mathrm{MgCl}_{2}, 1$; glucose, 10; HEPES, 10; and bovine serum albumin, $0.1 \mathrm{mg} / \mathrm{ml}, \mathrm{pH} 7.4,270 \mathrm{mOsm}$. In the high-Ca ${ }^{2+}$ solution, the concentration of $\mathrm{Ca}^{2+}$ was raised from 2.5 to $3.5 \mathrm{mM}$, and $\mathrm{Mg}^{2+}$ was omitted. In the $\mathrm{Co}^{2+}$ solution, $3.5 \mathrm{~mm} \mathrm{CoCl}$ was substituted for $\mathrm{CaCl}_{2}$ and $\mathrm{MgCl}_{2}$. PMA (Sigma, St. Louis, MO) and BIS (Calbiochem, San Diego, CA) were dissolved in dimethylsulfoxide (DMSO) and stocked in a refrigerator. Test solutions were made by diluting the stock solutions with the control solution before experiments. The final DMSO concentration was $\leq 0.02 \%$. Test solutions were applied from a Y-tube microflow system (Suzuki et al., 1990), the tip of which was placed in the vicinity of a whole-cell clamped cell.

Whole-cell recordings. The pipette solution contained (in $\mathrm{mm}$ ): $\mathrm{CsCl}$, 135; HEPES, 10; BAPTA, 0.2; $\mathrm{MgCl}_{2}, 2$; $\mathrm{Na}_{2}$-ATP, 2; and $\mathrm{Na}_{3}$-GTP, 0.5 , $\mathrm{pH} 7.2,270 \mathrm{mOsm}$. Conventional whole-cell recordings were performed with EPC-9/2 (Heka, Lambrecht, Germany), which was controlled by the Pulse software (Heka). Membrane capacitance $\left(C_{\mathrm{m}}\right)$ changes were measured in the "sine + DC" mode (Gillis, 1995) of lock-in extension of the Pulse software, with a $1 \mathrm{kHz}$ sine wave ( $30 \mathrm{mV}$ peak-to-peak) superimposed on the holding potential of $-60 \mathrm{mV} . C_{\mathrm{m}}$ was averaged over $100-200$ cycles of the sine wave. $C_{\mathrm{m}}$ changes associated with exocytosis (capacitance jumps; $\Delta C$ ) were calculated as the difference of $C_{\mathrm{m}} 1 \mathrm{msec}$ before and $20 \mathrm{msec}$ after the application of a test pulse. For all $C_{\mathrm{m}}$ traces analyzed, changes in series conductance $\left(G_{\mathrm{s}}\right)$ did not correlate with $C_{\mathrm{m}}$ changes. $G_{\mathrm{s}}$, basal $C_{\mathrm{m}}$, and pipette resistance were in the range of $40-60$ $\mathrm{nS}, 2.5-4.0 \mathrm{pF}$, and $10-14 \mathrm{M} \Omega$, respectively. Liquid junction potential was not corrected. Voltage stimuli were delivered every $40 \mathrm{sec}$ to allow for a complete recovery from vesicle depletion. Currents were low-pass filtered at $3 \mathrm{kHz}$ and sampled at every $100 \mu \mathrm{sec}$. Leak currents were measured in the $\mathrm{Co}^{2+}$ solution and were $<40 \mathrm{pA}$. Analysis was performed off-line by the IgorPro software (Wavemetrics, Lake Oswego, OR).

Estimation of the pool size and release probability. The pool size of releasable synaptic vesicles and release probability were estimated by the double-pulse protocol (Gillis et al., 1996). Two $200 \mathrm{msec}$ pulses were 
applied to bipolar terminals with an interval of $300 \mathrm{msec}$ (Fig. 1A). The capacitance jump induced by the first pulse $\left(\Delta C_{1}\right)$ is given as follows:

$$
\Delta C_{1}=B_{1} \alpha_{1},
$$

where the initial pool size and release probability are denoted by $B_{1}$ and $\alpha_{1}$, respectively. $B_{1}$ is the number of releasable synaptic vesicles multiplied by the average capacitance of a single vesicle $(26 \mathrm{aF}$; von Gersdorff et al., 1996). $\alpha_{1}$ is a fraction of the fused vesicles in the releasable pool. To solve this equation, it is necessary to assume the pool size and release probability after the application of the first pulse. Concerning the pool size, we assume that the replenishment of the releasable pool is negligible during the interval of $300 \mathrm{msec}$ between two pulses because this interval is very short comparing with the time constant of $8 \mathrm{sec}$, with which the releasable pool in bipolar cells recovers from vesicle depletion (von Gersdorff and Matthews, 1997). Under this assumption the second capacitance jump, $\Delta C_{2}$, can be calculated by multiplying the remaining pool after the first pulse by the second release probability, $\alpha_{2}$ :

$$
\Delta C_{2}=B_{1}\left(1-\alpha_{1}\right) \alpha_{2} .
$$

Concerning the release probability, two cases are assumed. In the first case it is assumed that release probability remains constant after the application of the first pulse. Under this assumption, Equation 2 can be revised as follows:

$$
\Delta C_{2}=B_{1}\left(1-\alpha_{1}\right) \alpha_{1}
$$

To satisfy this assumption, the $\mathrm{Ca}^{2+}$ influx induced by the second pulse should be identical to that by the first pulse. Thus, we adjusted the amplitude of the second pulse during the double-pulse experiment. Equations 1 and 2 ' yield:

$$
\begin{aligned}
& B_{1}^{\prime}=\frac{\Delta C_{1}^{2}}{\Delta C_{1}-\Delta C_{2}} \\
& \alpha_{1}^{\prime}=\frac{\Delta C_{1}-\Delta C_{2}}{\Delta C_{1}}
\end{aligned}
$$

In the second case it is assumed that the probability of $\alpha_{2}$ increases to 1 after the application of the first pulse because it is possible that the residual $\mathrm{Ca}^{2+}$ after the first pulse may facilitate exocytosis induced by the second pulse (Kamiya and Zucker, 1994; Debanne et al., 1996). Under this assumption, $\Delta C_{2}$ is all of the rest after the first pulse:

$$
\Delta C_{2}=B_{1}\left(1-\alpha_{1}\right)
$$

The equations (1) and (2") yield:

$$
\begin{aligned}
& B_{1}^{\prime \prime}=\Delta C_{1}+\Delta C_{2} \\
& \alpha_{1}^{\prime \prime}=\frac{\Delta C_{1}}{\Delta C_{1}+\Delta C_{2}}
\end{aligned}
$$

If $\alpha_{2}$ lies somewhere between $\alpha_{1}$ and 1 , the estimates based on the equation $\left(2^{\prime}\right)$ give us the maximum for the pool size $\left(B^{\prime}{ }_{1}\right)$ and the minimum for release probability $\left(\alpha^{\prime}{ }_{1}\right)$, whereas the estimates based on the equation $\left(2^{\prime \prime}\right)$ give the minimum for the pool size $\left(B^{\prime \prime}{ }_{1}\right)$ and the maximum for release probability $\left(\alpha^{\prime \prime}{ }_{1}\right)$. The range of the estimated pool size (minimum and maximum) becomes narrow when release probability is high. To reduce the range of estimation, the pulse duration was set long enough to give a high release probability $(>0.7)$.

The estimation of the pool size and release probability is based on the assumption that release probability of synaptic vesicles in the releasable pool is homogenous. However, synaptic vesicles in the releasable pool of $\mathrm{Mb} 1$ bipolar cells are divided into two components. A subset of the pool (a fast component: $\sim 30 \mathrm{fF}$ or $\sim 1200$ synaptic vesicles) is released much faster and exhausted much easily than the rest (a slow component: $\sim 120$ fF or $\sim 4800$ synaptic vesicles) upon stimulation (Mennerick and Matthews, 1996; Sakaba et al., 1997b). If the fast component is depleted during the first pulse, and only the remaining slow component becomes available, the apparent release probability during the second pulse would decrease (Sakaba and Neher, 2001), resulting in an underestimate of the pool size and an overestimate of release probability. To evaluate whether the estimation of the pool size by the double-pulse protocol is actually affected by the depletion of the fast component by the first pulse, we compared the size of the releasable pool estimated by the $200 \mathrm{msec}$ double-pulse protocol and that by a single $500 \mathrm{msec}$ pulse, which is long enough to deplete the releasable pool (von Gersdorff and Matthews, 1994; Mennerick and Matthews, 1996; Sakaba et al., 1997b). The maximum $\left(B^{\prime}{ }_{1}\right)$ and minimum $\left(B^{\prime \prime}{ }_{1}\right)$ of the pool size estimated by the doublepulse protocol was $108.0 \pm 4.9$ and $96.6 \pm 6.2 \%(n=6)$ of the value estimated by the single long pulse, respectively. Therefore, the depletion of the fast component by the first pulse seemed to be negligible for the estimation of the size of the releasable pool. To examine the effects of the PKC activation on two components of transmitter release separately, we applied two double-pulses that could deplete the fast and slow components successively, and estimated the pool size and release probability of two components independently (see Results).

\section{RESULTS}

\section{Estimation of the pool size and release probability by the double-pulse protocol}

The pool size and release probability were estimated by applying two successive depolarizing pulses to a terminal detached from the Mb1 bipolar cell (Fig. $1 A$ ). A depolarization to $0 \mathrm{mV}$ induced an inward current. This current was carried mostly by $\mathrm{Ca}^{2+}$ because the $\mathrm{Ca}^{2+}$-activated $\mathrm{K}^{+}$current (Kaneko and Tachibana, 1985; Sakaba et al., 1997a) was suppressed by internal $\mathrm{Cs}^{+}$and because the contamination of the $\mathrm{Ca}^{2+}$-activated $\mathrm{Cl}^{-}$current (Okada et al., 1995) was minimized by depolarizing the membrane potential close to $\mathrm{E}_{\mathrm{Cl}}(+0.1 \mathrm{mV})$. A $200 \mathrm{msec}$ pulse to $0 \mathrm{mV}$ is sufficient to deplete mostly the releasable synaptic vesicles (Mennerick and Matthews, 1996; Sakaba et al., 1997b). When two $200 \mathrm{msec}$ pulses were applied with a $300 \mathrm{msec}$ interval, the capacitance jump for the second pulse $\left(\Delta C_{2}\right)$ was much smaller than that for the first one $\left(\Delta C_{1}\right)$, indicating that releasable synaptic vesicles decreased in number after the first pulse (Fig. 1A). This phenomenon is considered as a form of synaptic depression with a presynaptic origin (von Gersdorff and Matthews, 1997). The pool size of releasable synaptic vesicles and release probability were estimated from capacitance jumps (see Materials and Methods). The amount of $\mathrm{Ca}^{2+}$ influx $\left(Q_{\mathrm{Ca}}\right.$; the shadow region of $I_{\mathrm{Ca}}$ in Fig. $1 A$ ) was calculated by integrating $I_{\mathrm{Ca}}$ during the pulse after subtraction of the leak current obtained in the $\mathrm{Co}^{2+}$ solution (a nearly flat trace in Fig. $1 A$ ). $\mathrm{Ca}^{2+}$ influx after the cessation of the pulse was negligibly small because $\mathrm{Ca}^{2+}$ tail current lasted only for a few milliseconds and because the slow tail-like inward current was carried not by $\mathrm{Ca}^{2+}$ but by $\mathrm{Cl}^{-}$(Okada et al., 1995). To minimize the effect of $\mathrm{Ca}^{2+}$ channel inactivation on exocytosis, the intensity of the second pulse was appropriately adjusted by a few millivolts. $Q_{\mathrm{Ca} 2}$ was $94.3 \pm 0.6 \%$ (mean $\pm \mathrm{SEM}$; $n=21$ ) of $Q_{\mathrm{Ca} 1}$. The charge carried by $\mathrm{Cl}^{-}$during the second pulse was estimated to be $<2 \%$ of $Q_{\mathrm{Ca} 2}$.

The validity of the double-pulse protocol was tested by changing $\left[\mathrm{Ca}^{2+}\right]_{\mathrm{o}}$, which affects release probability more strongly than the pool size (Dodge and Rahamimoff, 1967; Llinás et al., 1981). When $\left[\mathrm{Ca}^{2+}\right]_{\mathrm{o}}$ was decreased from 3.5 to $2.5 \mathrm{~mm}$, both $I_{\mathrm{Ca}}$ and the capacitance jump evoked by the first pulse $\left(\Delta C_{1}\right)$ were reduced, and the degree of depression $\left(\Delta C_{2} / \Delta C_{1}\right)$ became small (Fig. $1 A, 3.5 \mathrm{Ca}$ and $2.5 \mathrm{Ca}$ ). Two parameters (the pool size and release probability) were estimated based on the assumptions (see Materials and Methods). The means and SEM values for each parameter are shown in Figure $1 B$. Because release probability was not yet saturated but as high as 0.8 (Fig. $1 B c$ ), two different assumptions $\left(\alpha_{2}=\alpha_{1}\right.$ or $\left.\alpha_{2}=1\right)$ yielded almost the same estimates (Fig. $1 B b, c$ ). The actual values should be within these narrow limits. When $\left[\mathrm{Ca}^{2+}\right]_{\mathrm{o}}$ was decreased from 3.5 to $2.5 \mathrm{~mm}$, $Q_{\text {Ca }}$ decreased significantly. This procedure induced a significant decrease in release probability but did not change the pool size. After $\left[\mathrm{Ca}^{2+}\right]_{\mathrm{o}}$ was returned to $3.5 \mathrm{~mm}, Q_{\mathrm{Ca}}$ and release proba- 


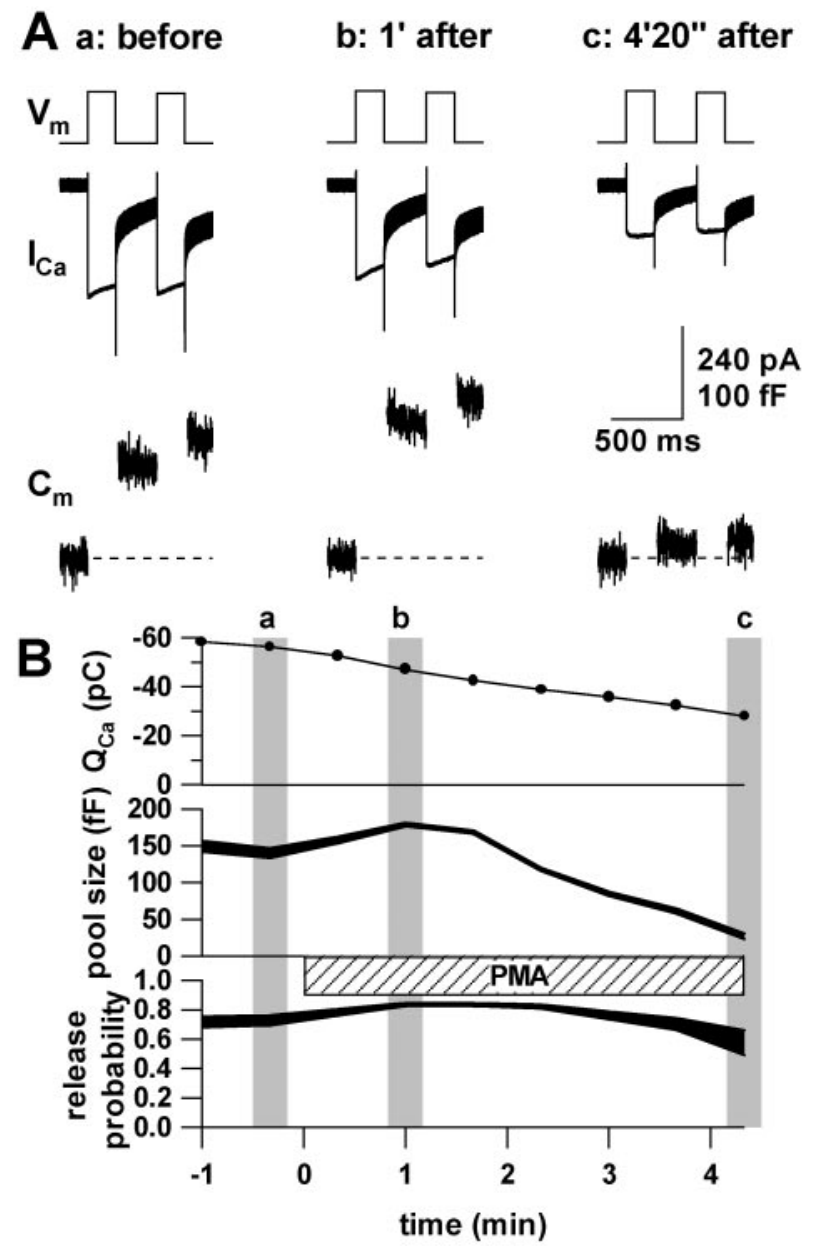

Figure 2. Effects of PMA on the pool size and release probability. $A, I_{\mathrm{Ca}}$ and $C_{\mathrm{m}}$ before and during the application PMA (100 nM). Double pulses $\left(V_{\mathrm{m}}\right)$ were applied to a detached terminal repetitively at intervals of 40 sec. Each set of $V_{\mathrm{m}}, I_{\mathrm{Ca}}$, and $C_{\mathrm{m}}$ was obtained before $(a), 1 \mathrm{~min}$ after $(b)$, and 4 min $20 \mathrm{sec}$ after $(c)$ the application of PMA. $B$, Time course of changes in $Q_{\mathrm{Ca}}$, the pool size and release probability before and during the application of PMA (horizontal bar). The thickness of lines in the graphs of the pool size and release probability depicts the range of maximums and minimums of estimation. Original traces shown in $A$ were recorded at the corresponding periods ( $a-c$, gray zones).

bility significantly increased, although $Q_{\mathrm{Ca}}$ and the pool size showed a tendency to rundown. This control experiment indicates that the pool size and release probability can be estimated properly by the double-pulse protocol.

\section{Increase in the pool size of releasable synaptic vesicles by the activation of PKC}

To determine whether the enhancement of transmitter release induced by the activation of PKC is ascribed to the increase in the pool size or release probability, the double-pulse protocol was applied to a terminal detached from the Mb1 bipolar cell before and during the application of PKC activator, PMA (100 nM) (Fig. $2 A$ ). One minute after the application of PMA (Fig. $2 A b$ ), both the capacitance jump evoked by the first pulse $\left(\Delta C_{1}\right)$ and the total capacitance jump evoked by the double pulse $\left(\Delta C_{1}+\Delta C_{2}\right)$ became larger than the control (Fig. $2 A a$ ). The degree of depression $\left(\Delta C_{2} / \Delta C_{1}\right)$ was also increased.

Figure $2 B$ illustrates the changes in $Q_{\mathrm{Ca}}$, the pool size and release probability before and during the application of PMA.
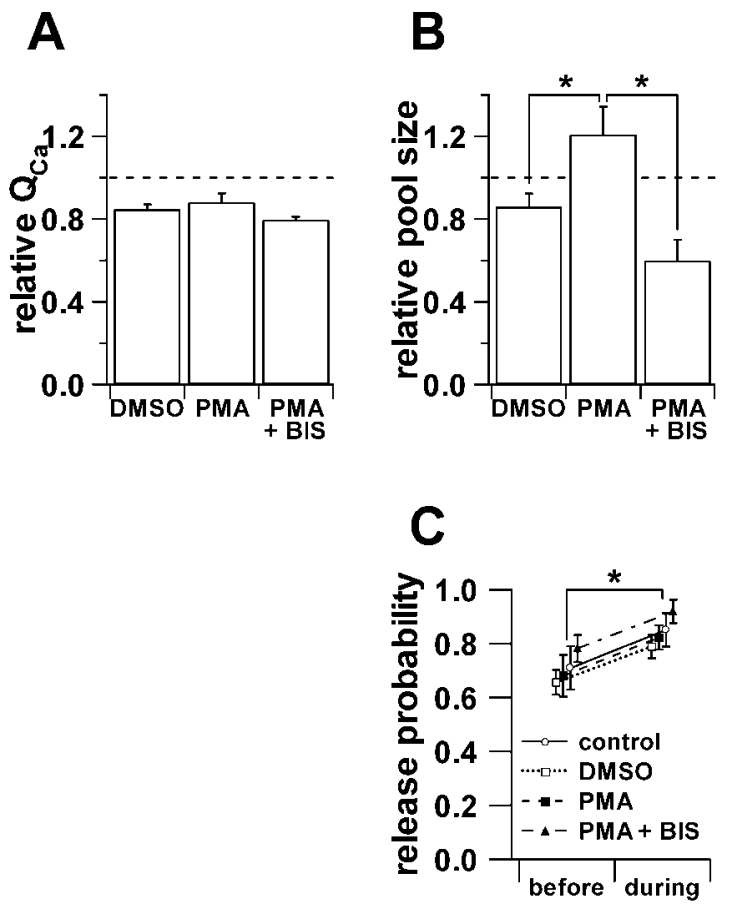

Figure 3. Evaluation of the specificity for PMA-induced changes. $A$, Changes in $Q_{\mathrm{Ca}}$ after the introduction of DMSO $(1: 10,000 \mathrm{v} / \mathrm{v} ; n=11)$, PMA (10 or $100 \mathrm{nM}$ with DMSO; $n=5$ ), or PMA plus BIS (500 nM with DMSO; $n=4)$. Relative values indicate the ratio of $Q_{\mathrm{Ca}} 1 \mathrm{~min} 40 \mathrm{sec}$ after the application of each agent to $Q_{\mathrm{Ca}}$ before its application. $B$, Changes in the pool size after the application of each agent. The pool size in this and the subsequent figures refers to the maximum of estimation. Relative values were calculated with the data obtained at the same timing as in $A$. Asterisks denote significant differences in the two-tailed Student's $t$ test $(p<0.05) . C$, Changes in release probability after the application of each agent. Release probability in this and the subsequent figures refers to the minimum of estimation. In the control condition, no agent was added to the superfusate, and data were obtained at the corresponding time to the other conditions $(n=5)$. Significant difference (asterisk) was detected only in the main effect of time (before/after application), and neither in the main effect of agents nor in the interaction (the two-way ANOVA; four conditions $\times$ before/after application; $p<0.05$ ).

$Q_{\text {Ca }}$ showed a tendency to rundown with time. The estimated values for the pool size and release probability are illustrated with maximums and minimums. The pool size increased 1 min after the PMA application and then rapidly decreased. Release probability increased slightly $1 \mathrm{~min}$ after the PMA application and then gradually decreased. Because release probability is sensitive to $\mathrm{Ca}^{2+}$, as shown in Figure 1, a part of the decrease in release probability may be ascribed to the rundown of $Q_{\mathrm{Ca}}$. This experiment suggests that PMA may affect both pool size and release probability.

Next, we examined whether the increase in both parameters shortly after the application of PMA was specifically caused by the activation of PKC. The double-pulse protocol was applied to the detached terminals, which were superfused with one of three kinds of test solutions. The test solutions contained either (1) the solvent alone (DMSO), (2) PMA with DMSO, or (3) a specific inhibitor of PKC (BIS, $500 \mathrm{~nm}$ ) plus PMA with DMSO. After the application of any test solutions by the Y-tube microflow system, $Q_{\text {Ca }}$ decreased similarly (Fig. $3 A$ ). There were no significant differences among three conditions. Thus, the decrease in $Q_{\mathrm{Ca}}$ simply reflects the rundown with time. The pool size increased significantly only when the test solution 2 (PMA with DMSO) was 
applied (Fig. 3B). BIS could antagonize the effect of PMA, indicating that the increase in the pool size by PMA is caused by the activation of PKC. On the other hand, release probability was increased after the introduction of any agents (Fig. 3C). Even when no agent was applied (Fig. $3 C$, control), release probability increased with time. The increase in release probability was not caused by a mechanical artifact of switching solutions by the Y-tube microflow system because release probability increased gradually with time without switching solutions (data not shown). The two-way ANOVA (four conditions $\times$ before/after application) showed no significant interaction $(p>0.9)$. Only the main effect of time (before/after application) was significant $(p<0.05)$. Therefore, we conclude that the increase in release probability after the application of PMA (Figs. $2 B, 3 C$ ) is not specific to the activation of PKC.

If the activation of PKC does not alter release probability, the alternation of $\left[\mathrm{Ca}^{2+}\right]_{0}$ may not affect the extent of the PMAinduced increase in the pool size. To avoid the saturation of release probability at a high $\left[\mathrm{Ca}^{2+}\right]_{0}$, the pool size was estimated at a low $\left[\mathrm{Ca}^{2+}\right]_{\mathrm{o}}$. However, as mentioned in Materials and Methods, the range of the estimated pool size (minimum and maximum) becomes wider when release probability is low. Thus, the pool size was estimated from the capacitance jump evoked by the first $200 \mathrm{msec}$ pulse in the double pulse protocol. PMA increased the capacitance jump by $47.5 \pm 6.9 \%(n=5)$ in $2.5 \mathrm{~mm}\left[\mathrm{Ca}^{2+}\right]_{\mathrm{o}}$, whereas by $43.3 \pm 14.8 \%(n=5)$ in $1.0 \mathrm{~mm}\left[\mathrm{Ca}^{2+}\right]_{0}$. The increase was not statistically different between two $\left[\mathrm{Ca}^{2+}\right]_{\mathrm{o}}$ conditions (the two tailed Student's $t$ test; $p>0.8$ ). Therefore, it is concluded that the specific effect of PMA on PKC in goldfish retinal Mb1 bipolar cells is to increase the pool size of releasable synaptic vesicles.

\section{Activation of PKC without $\mathrm{Ca}^{2+}$ influx}

In the experiments described above, bipolar cells were depolarized repetitively before and during the application of PMA. It is not clear whether the $\mathrm{Ca}^{2+}$ influx induced by depolarizing pulses is essential for the PKC activation by PMA. To examine whether PMA can activate PKC near the resting level of internal $\mathrm{Ca}^{2+}$ concentration $\left(\left[\mathrm{Ca}^{2+}\right]_{\mathrm{i}}\right)$, bipolar terminals were preincubated with PMA, during which time $\mathrm{Ca}^{2+}$ channels of the terminals were blocked by $\mathrm{Co}^{2+}$, and no depolarizing pulses were applied (Fig. 4). $Q_{\mathrm{Ca}}$ declined with time even when the $\mathrm{Ca}^{2+}$ influx was suppressed by $\mathrm{Co}^{2+}$ (Fig. 4A, top, solid circles). Shortly after the start of $\mathrm{Co}^{2+}$ washout, $Q_{\mathrm{Ca}}$ increased transiently, perhaps because of unbinding of $\mathrm{Co}^{2+}$ from $\mathrm{Ca}^{2+}$ channels. The rundown of $Q_{\mathrm{Ca}}$ appeared slightly faster in the PMA-treated terminal (Fig. $4 A$, top, solid circles) than the PMA-untreated terminal (open circles), but this difference was not statistically significant (Fig. 4B).

Preincubation of the terminal with PMA without $\mathrm{Ca}^{2+}$ influx induced a marked increase in the pool size estimated by the resumed first double pulse (Fig. $4 A$, middle, solid squares). The pool size increased twice as much as that before the application of PMA. The PMA pretreatment significantly increased the pool size (Fig. 4C) but did not affect release probability (Fig. 4A, bottom, $D)$. This series of experiments suggests that PMA may activate $\mathrm{PKC}$ of $\mathrm{Mb} 1$ bipolar cells even after the $\mathrm{Ca}^{2+}$ influx was blocked by $\mathrm{Co}^{2+}$.

The increased pool size rapidly decreased during repetitive stimulation in the presence of PMA, whereas without PMA treatment the pool size gradually decreased (Fig. 4A, middle, open squares). In the present study we concentrated on the anal-
A
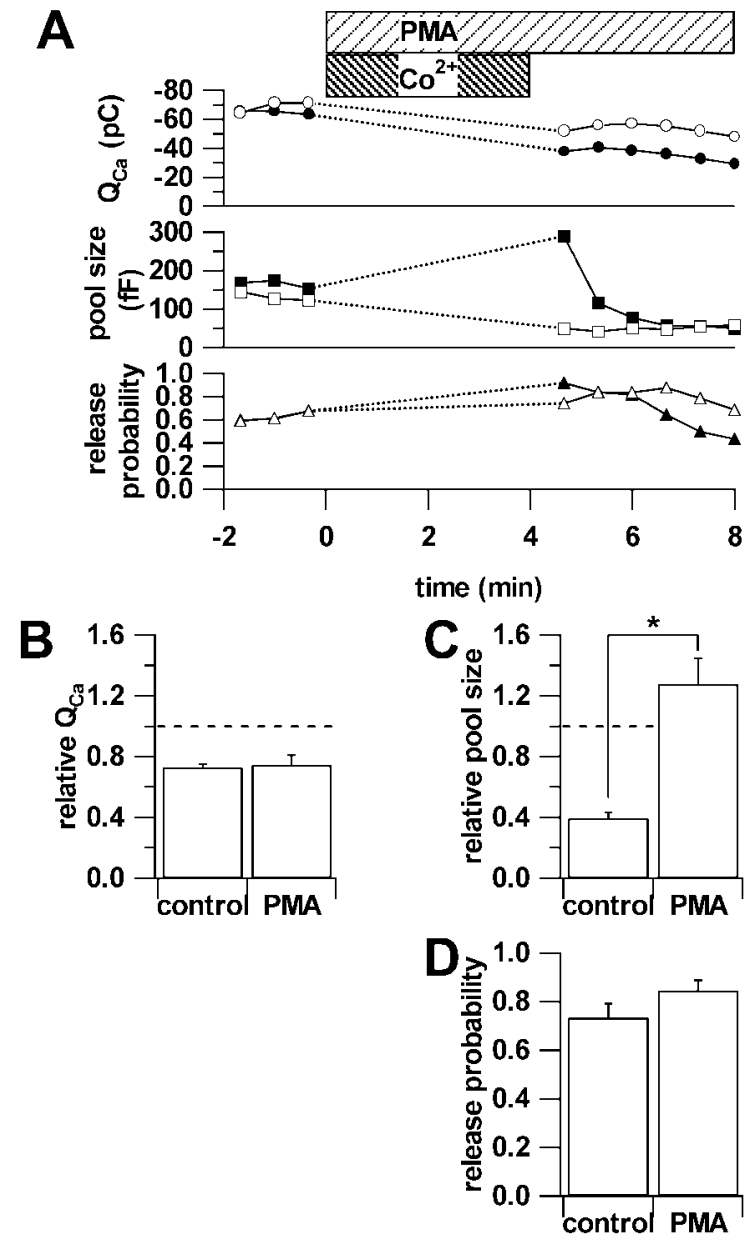

Figure 4. Activation of $\mathrm{PKC}$ at the resting $\left[\mathrm{Ca}^{2+}\right]_{\mathrm{i}} \cdot A, Q_{\mathrm{Ca}}$, the pool size, and release probability were estimated in the absence (open symbols) or in the presence (solid symbols) of PMA (100 nM). To suppress the $\mathrm{Ca}^{2+}$ influx into the terminals, double-pulse stimulation was interrupted in the presence of $\mathrm{Co}^{2+}$ for $5 \mathrm{~min}$. The periods of PMA and $\mathrm{Co}^{2+}$ treatment are indicated by horizontal bars. The pool size of the PMA-treated terminal increased soon after the double pulse was resumed (solid squares). Bar graphs illustrate the relative values of $Q_{\mathrm{Ca}}(B)$, of the pool size $(C)$, and release probability $(D)$. The relative values were the ratio of the values obtained 5 min after the application of the $\mathrm{Co}^{2+}$ solution to those before its application. The pool size was significantly increased by the PMA treatment $\left({ }^{*} p<0.05\right.$, the two-tailed Student's $t$ test; $n=5$ in each condition).

ysis of the potentiation mechanism, and we did not pursue the reason why the pool size rapidly decreased after potentiation.

\section{Modulation of the slow component of exocytosis by PKC}

As mentioned in Materials and Methods, synaptic vesicles in the releasable pool of $\mathrm{Mb} 1$ bipolar cells are divided into the fast component ( $\sim 30 \mathrm{fF}$ or $\sim 1200$ synaptic vesicles) and the slow component ( $\sim 120 \mathrm{fF}$ or $\sim 4800$ synaptic vesicles) (Mennerick and Matthews, 1996; Sakaba et al., 1997b). A $10 \mathrm{msec}$ depolarization can completely deplete the fast component (Mennerick and Matthews, 1996; Sakaba et al., 1997b), whereas a 200 msec depolarization can deplete most of the slow component, as shown in the previous section (see also von Gersdorff et al., 1998). Now we examined which component is potentiated by the activation of PKC.

To separate these two components, the two double-pulse protocol was used (Fig. $5 A$ ). A $5 \mathrm{msec}$ double pulse was applied to 
A before PMA
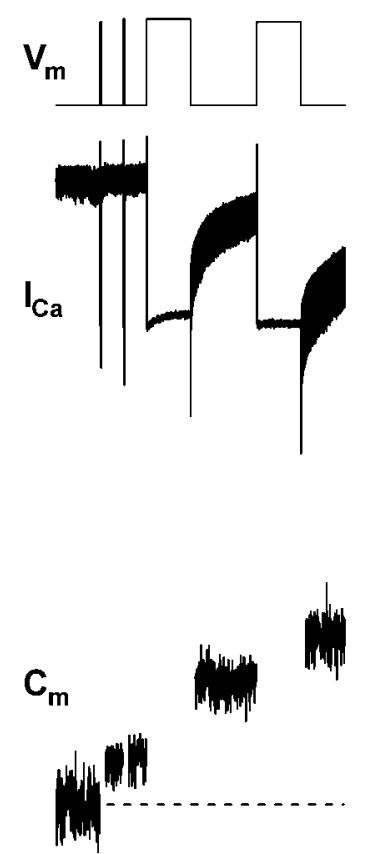

during PMA

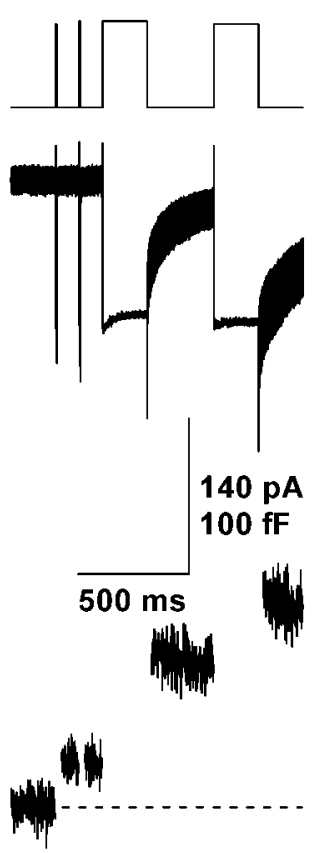

B a

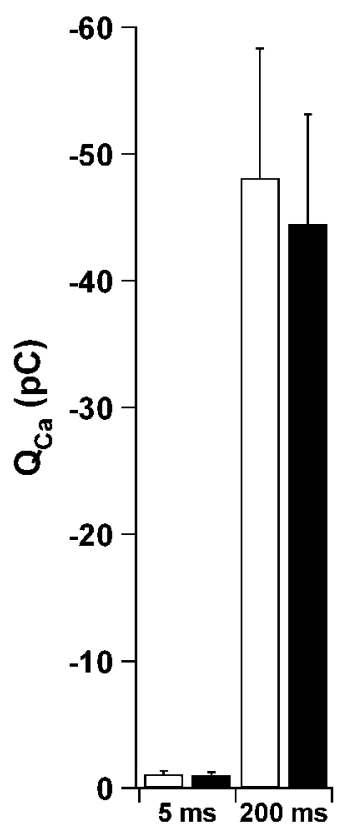

b

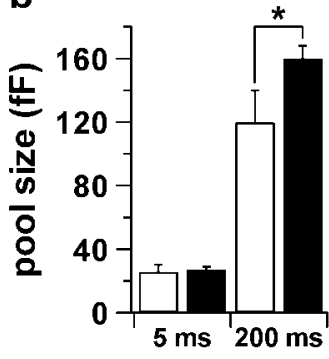

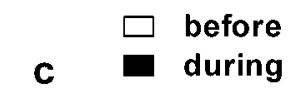

$\left.\begin{array}{ll|l|}\frac{2}{2} & 1.0 \\ \frac{0}{0} & 0.8\end{array}\right]$

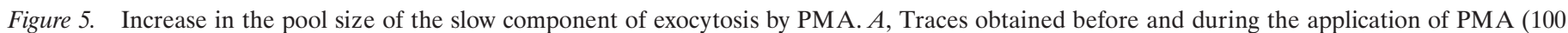

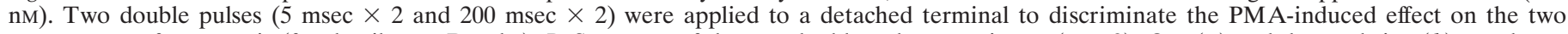

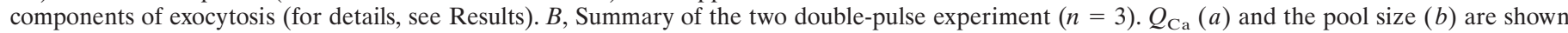

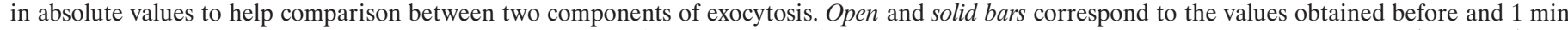
$40 \mathrm{sec}$ after the application of PMA, respectively. An asterisk denotes a significant difference in the two-tailed, paired Student's $t$ test $(p<0.05)$.

examine the pool size of the fast component. Then, a $200 \mathrm{msec}$ double pulse was applied to estimate the pool size of the slow component. $C_{\mathrm{m}}$ was increased after the first $5 \mathrm{msec}$ pulse, whereas the second $5 \mathrm{msec}$ pulse elicited almost no $C_{\mathrm{m}}$ change, indicating that the first $5 \mathrm{msec}$ pulse was strong enough to deplete the fast component. The first $200 \mathrm{msec}$ pulse could elicit a much larger capacitance jump than the first $5 \mathrm{msec}$ pulse, indicating that transmitter was released from the slow component after the depletion of the fast component. The capacitance jump evoked by the second $200 \mathrm{msec}$ pulse was much smaller than that by the first $200 \mathrm{msec}$ pulse, suggesting that the slow component was mostly depleted by the first $200 \mathrm{msec}$ pulse.

The pool size and release probability of each component were estimated independently by this protocol, and the effect of PMA on each component was evaluated separately. The capacitance jump evoked by the first $200 \mathrm{msec}$ pulse was increased by PMA, whereas the capacitance jump evoked by the first $5 \mathrm{msec}$ pulse was not obviously affected by PMA (Fig. $5 A$ ). The increase in the pool size of the slow component was statistically significant (Fig. 5Bb). The pool size of the fast component was not affected by PMA (Fig. $5 B b$ ). Nonsignificant increase in release probability of both components (Fig. $5 B C$ ) confirmed the previous observation (Figs. $2 B, 3 C)$. Therefore, we conclude that the activation of PKC by PMA increases mainly the pool size of the slow component.

\section{Basal activation of PKC}

The specific PKC inhibitor BIS could antagonize the effect of potentiation by PMA (Fig. 3B). Although the difference was not statistically significant, the pool size estimated in the presence of PMA and BIS (PMA plus BIS) was slightly smaller than that of control (DMSO alone). To examine a possibility that PKC may be partially activated even in the absence of PMA, BIS was intro- duced without PMA and the pool size was estimated by the two double-pulse protocol.

The pool size of the slow component began to decrease soon after the application of BIS (Fig. 6A, middle, open squares). On the other hand, the pool size of the fast component remained nearly constant at least for $1 \mathrm{~min}$ after the BIS application and then decreased (Fig. 6A, middle, solid squares). When DMSO alone was applied as control, the pool size of the slow component started decreasing earlier than that of the fast component (Fig. $6 C$ ). However, the extent of the pool size reduction of the slow component during 3 min application of test solutions was significantly larger for BIS than for control (DMSO alone). Neither $Q_{\mathrm{Ca}}$ nor release probability was affected by BIS; there observed a rundown of $Q_{\mathrm{Ca}}$ and a gradual increase in release probability with time (Fig. 6A). $Q_{\mathrm{Ca}}$ and release probability showed no consistent differences between BIS and control (DMSO alone) conditions (Fig. 6B,D). These results indicate that the pool size of the slow component is regulated by the basal activation of PKC.

\section{No effect of PMA on endocytosis}

Endocytosis, as well as exocytosis, is a highly regulated process (for review, see Cremona and De Camilli, 1997). Phosphorylation of endocytotic molecule or molecules by PKC may modulate membrane retrieval (Slepnev et al., 1998). Thus, we examined whether the time course of endocytosis is affected by the application of PMA.

Endocytosis was monitored as the decay from capacitance jumps after the application of double pulses. Figure 7 illustrates examples of $C_{\mathrm{m}}$ changes on a slow time scale, which were recorded in the control solution (Fig. $7 A$ ) and in the PMA solution (Fig. 7B). The application of depolarizing pulses evoked the increase in $C_{\mathrm{m}}$, which stayed at a plateau for a while and then 

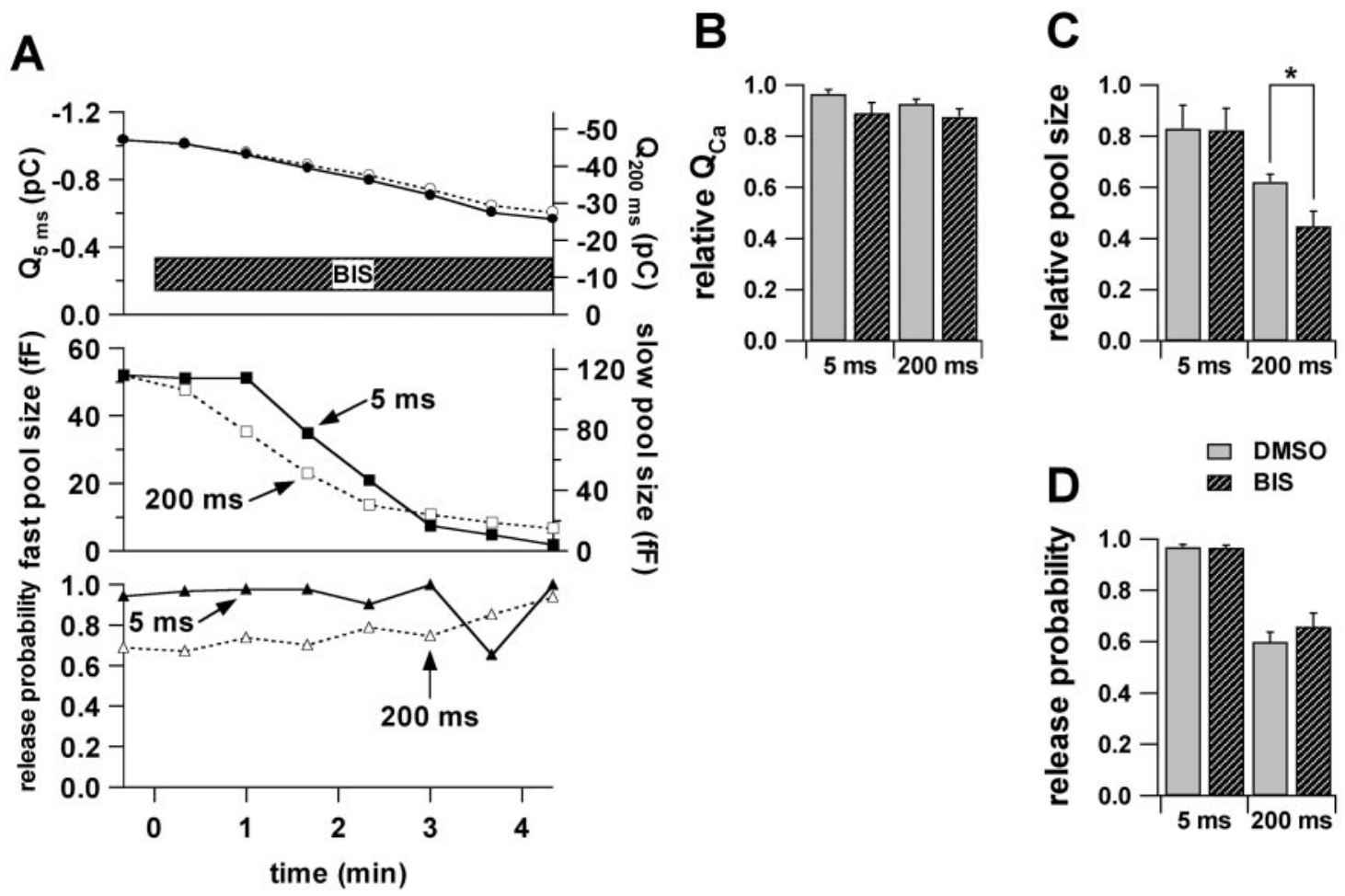

Figure 6. Decrease in the pool size of the slow component by BIS. A, Two double pulses (same as in Fig. 5) were repetitively applied to a detached terminal, and the effects of BIS (500 nM) on two components of exocytosis were examined separately. $Q_{\text {Ca }}$ (circles), the pool size (squares), and release probability (triangles) for each component are plotted against time after the BIS application (horizontal bar). The fast (solid symbols) and slow (open symbols) components of exocytosis were examined by 5 and $200 \mathrm{msec}$ double pulses, respectively. The decrease in the pool size of the slow component (open squares) preceded that of the fast component (solid squares). $B-D$, Summary of the two double pulse experiment in the presence of DMSO $(1: 10,000 \mathrm{v} / \mathrm{v}$; open bars, $n=5)$ and BIS (with DMSO, solid bars; $n=5)$. The relative values of $Q_{\mathrm{Ca}}(B)$ and the pool size $(C)$ are calculated as in Figure 3. Release probability is shown in $D$. Values obtained by three successive stimuli $(1 \mathrm{~min} 40 \mathrm{sec}, 2 \mathrm{~min} 20 \mathrm{sec}$, and 3 min after drug application) were averaged. An asterisk denotes a significant difference in the two-tailed Student's $t$ test $(p<0.05)$.

decayed exponentially. von Gersdorff and Matthews (1999) have reported such delay of endocytosis in Mb1 bipolar cells. In addition to the depolarization-induced $C_{\mathrm{m}}$ changes, the basal level of $C_{\mathrm{m}}$ usually decreased gradually for $>5 \mathrm{~min}$ after the establishment of the whole-cell configuration.

We quantified the gradual basal change of $C_{\mathrm{m}}$ (trend), and the delay and decay time constant $(\tau)$ after the capacitance jump evoked by depolarization. The trend was determined by fitting a regression line to a gradually decreasing basal $C_{\mathrm{m}}$ (in this Figure, the $C_{\mathrm{m}}$ trace before the application of a double pulse). After subtraction of the trend, a single exponential function was fitted to the decay phase of the capacitance jump, and $\tau$ was calculated. A line with the same slope as the trend was drawn to fit the plateau after the pulse. The delay was defined as the time between the termination of the pulse and the intersection of the line and the exponential curve. The application of PMA caused no significant differences in these three measures (Fig. 7C). Therefore, it is unlikely that endocytosis is affected by the activation of PKC.

\section{DISCUSSION}

\section{Membrane capacitance measurement and the double-pulse protocol}

In the present study, we applied the double-pulse protocol to the terminals detached from Mb1 bipolar cells of the goldfish retina and measured the presynaptic $I_{\mathrm{Ca}}$ and $C_{\mathrm{m}}$ changes associated with exocytosis and endocytosis. This technique enabled us to analyze quantitatively the effects of PMA on transmitter (glutamate) release. Furthermore, we could estimate the changes of the pool size and release probability separately. In our previous study (Minami et al., 1998), glutamate release was monitored by a bioassay technique: the terminal of an Mb1 bipolar cell was closely apposed to an NMDA-receptor rich neuron under the voltage clamp, and the presynaptic $I_{\mathrm{Ca}}$ and the current through NMDA receptors was simultaneously recorded. This technique allowed us a qualitative analysis of transmitter release, but it was difficult to monitor endocytosis and to estimate separately the pool size and release probability.

In the double-pulse protocol, bipolar cells show almost a saturating $C_{\mathrm{m}}$ change to the first depolarizing pulse (to $0 \mathrm{mV}$ for 200 $\mathrm{msec}$ ), resulting in potent depression of transmitter release to the second depolarizing pulse. Our estimation of two parameters (the pool size and release probability) relies on the assumption that the observed depression is caused by a decrease in releasable synaptic vesicles. Synaptic depression can be observed when postsynaptic receptors are saturated or desensitized, or when presynaptic $I_{\mathrm{Ca}}$ is inactivated after the first depolarizing pulse. However, these possibilities do not affect the present study because transmitter release was quantified by capacitance jumps in the detached presynaptic terminals and because $I_{\mathrm{Ca}}$ was monitored and adjusted to minimize the inactivation of presynaptic $\mathrm{Ca}^{2+}$ channels.

\section{Comparison of the present results with our previous ones}

The present study confirmed the main part of our previous results (Minami et al., 1998). First, PMA enhances exocytosis through 
A before PMA B during PMA
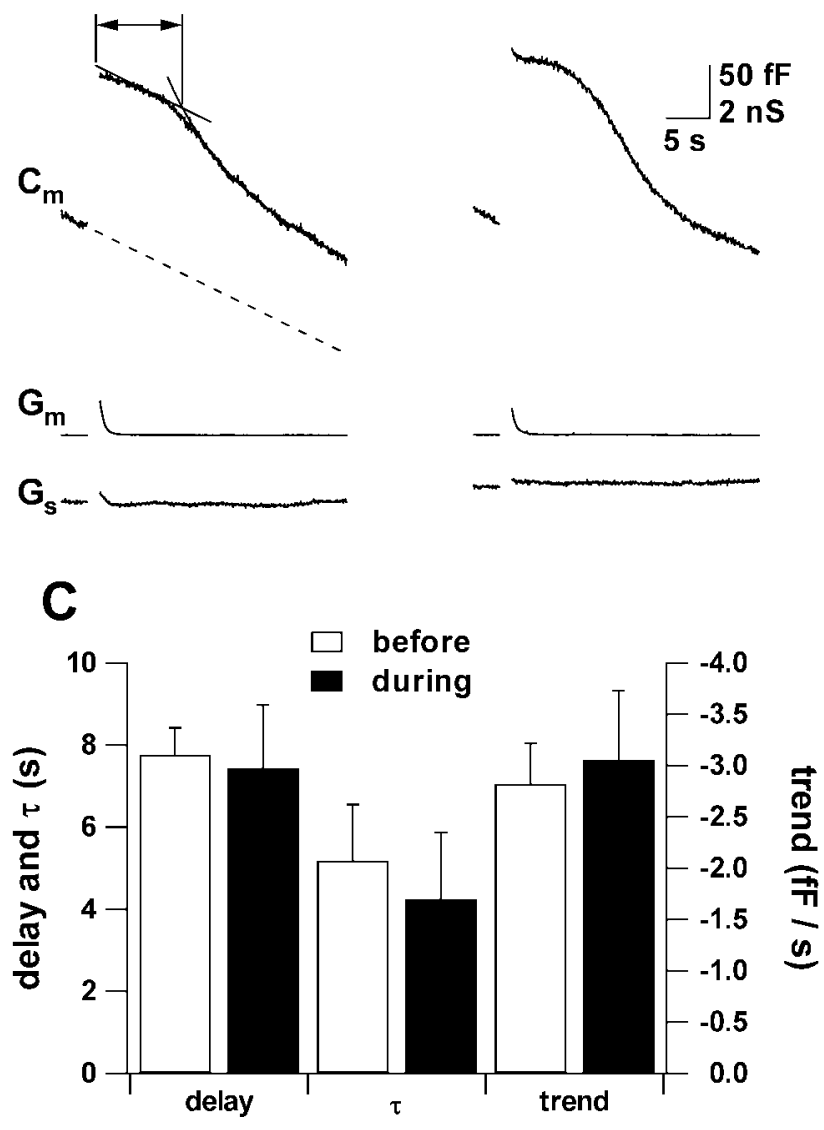

Figure 7. No effect of PMA on endocytosis. $A, B$, The membrane capacitance $\left(C_{\mathrm{m}}\right)$, the membrane conductance $\left(G_{\mathrm{m}}\right)$, and the series conductance $\left(G_{\mathrm{s}}\right)$ are calculated before $(A)$ and $1 \mathrm{~min}$ after $(B)$ the application of PMA (100 nM). Traces are illustrated on a slow time scale. Double pulse stimulation was applied during the gaps of traces in each panel. The values of $C_{\mathrm{m}}$ before stimulation were $3.78 \mathrm{pF}(A)$ and $3.44 \mathrm{pF}$ $(B)$. The values of $G_{\mathrm{m}}$ and $G_{\mathrm{s}}$ before the application of PMA $(A)$ were 0.164 and $38.8 \mathrm{nS}$, respectively. The transient jump in $G_{\mathrm{m}}$ after the pulse may be ascribed to the activation of the $\mathrm{Ca}^{2+}$-dependent $\mathrm{Cl}^{-}$current (Okada et al., 1995) but did not affect the measurement of $C_{\mathrm{m}} . C$, The trend (dotted line), the delay (line with arrowheads), and the time constant of the decay $(\tau)$ determined by fitting an exponential function (smooth curve) were calculated before (open bars) and during the application of PMA (solid bars), as described in Results. These three parameters of endocytosis were not significantly changed by the application of PMA $(p>0.1$; the two-tailed, paired Student's $t$ test; $n=5)$.

the activation of PKC (Fig. 3). It has been reported that an enhancement of transmitter release by phorbol ester is mediated not only by PKC but also by Munc13-1 (Betz et al., 1998; Hori et al., 1999). However, both of our results are attributable exclusively to the activation of PKC because BIS, a specific blocker that attacks ATP-biding site of PKC (Toullec et al., 1991), completely antagonized the effect of PMA (Hilfiker and Augustine, 1999; Brose et al., 2000) (Fig. 3). Second, PMA potentiates specifically the slow component of exocytosis but not the fast component (Fig. 5). Third, after the application of PMA, exocytosis is increased transiently and then rapidly decreased (Figs. 2, 4). The mechanism of the rapid decrease is yet to be solved.

The present study revealed several new findings. First, the PMA-induced potentiation of glutamate release is ascribed to an increase in the number of releasable synaptic vesicles and not to an increase in the content of glutamate packed in each synaptic vesicle (Figs. 2-5). The number of releasable synaptic vesicles actually increased from $\sim 5700$ to $\sim 11,400$ after the activation of PKC (Fig. 4A). Second, PMA potentiates exocytosis even when the $\mathrm{Ca}^{2+}$ influx is blocked by $\mathrm{Co}^{2+}$ (Fig. 4). Third, endocytosis is not affected by PMA (Fig. 7).

There is an apparent discrepancy between the present and previous results. The prolonged application of BIS without PMA could decrease the pool size of the slow component in the present study, whereas the previous study did not detect a significant decrease in glutamate release (Minami et al., 1998). However, as shown in Figure 6, BIS decreased the pool size, whereas release probability slightly increased with time. Because the amount of glutamate release monitored by the bioassay technique is a product of the pool size and release probability, the decrease in the pool size would not reflect the decrease in glutamate release. The previous study actually showed a slight decrease in the amount of glutamate release, but the decrease was not statistically significant.

\section{PKC isoforms responsible for the PMA-induced potentiation of exocytosis}

The goldfish Mb1 bipolar cells have at least two isoforms of PKC, PKC $\alpha$, a classical $\mathrm{Ca}^{2+}$-dependent type (Suzuki and Kaneko, 1990) and PKC $\epsilon$, a novel $\mathrm{Ca}^{2+}$-independent type (Osborne et al., 1994).

In the present study, it was demonstrated that PMA potentiated exocytosis even when the $\mathrm{Ca}^{2+}$ influx into terminals was suppressed by $\mathrm{Co}^{2+}$ (Fig. 4). Furthermore, PMA could enhance transmitter release from bipolar cells that were whole-cell voltage clamped with the pipette solution containing 5 mM EGTA (Minami et al., 1998). Because PKC $\epsilon$ is a $\mathrm{Ca}^{2+}$-independent type (Asaoka et al., 1992), it seems likely that PMA activates mainly $\mathrm{PKC} \epsilon$ in retinal bipolar cells. It has been reported in calyceal presynaptic terminals of rat brainstem that presynaptic PKC $\epsilon$ undergoes unidirectional translocation toward the synaptic side after stimulation with phorbol ester (Saitoh et al., 2001). They have also shown that phorbol ester-induced synaptic potentiation is not attenuated by chelating $\left[\mathrm{Ca}^{2+}\right]_{\mathrm{i}}$ with EGTA. Therefore, $\epsilon$-subspecies may be a crucial isoform of $\mathrm{PKC}$, which potentiates transmitter release.

In the presence of PMA, $\mathrm{Ca}^{2+}$-dependent PKCs such as $\mathrm{PKC} \alpha$ are fully activated by $\left[\mathrm{Ca}^{2+}\right]_{\mathrm{i}}$ at a range of $1 \mu \mathrm{M}$ (Castagna et al., 1982). Although both procedures used in our experiments could maintain the resting cytosolic $\left[\mathrm{Ca}^{2+}\right]_{\mathrm{i}}$ of bipolar cells at a level lower than $\sim 60 \mathrm{nM}$ (Kobayashi and Tachibana, 1995), $\left[\mathrm{Ca}^{2+}\right]_{\mathrm{i}}$ near the membrane would increase to a micromolar range once $\mathrm{Ca}^{2+}$ channels are activated. Therefore, PKC $\alpha$ may also contribute to the PMA-induced potentiation of transmitter release. However, its contribution would be small because the lowered cytosolic $\left[\mathrm{Ca}^{2+}\right]_{\mathrm{i}}$ may retard translocation of cytosolic PKC toward membrane by phorbol ester (Osborne et al., 1991).

\section{Two components of exocytosis in bipolar cells}

At the active zones of photoreceptors and bipolar cells in the retina, synaptic vesicles are concentrated near ribbons. Based on the electron-microscopic observation, von Gersdorff et al. (1996) proposed that the fast and slow components of transmitter release correspond to the docked vesicles at active zones near the corner between the ribbon and the plasma membrane, and the vesicles tethered to the ribbons, respectively. The model of von Gersdorff et al. (1996) implies that the tethered vesicles are recruited to the 
active zones after the docked vesicles are depleted. Recently, evanescence microscopy, a novel imaging technique to visualize exocytotic events in action, was applied to goldfish Mb1 bipolar cells, and the model of von Gersdorff et al. (1996) was confirmed in a living cell (Zenisek et al., 2000). They described two distinct fusion events at hot spots during stimulation: stationary (presumably docked) vesicles and then newly arrived vesicles fused into the plasma membrane. In the present study, the activation of PKC mainly affected the slow component of exocytosis, suggesting that the fast and slow components are implemented by different molecular bases. PKC may facilitate the arrival of new vesicles at active zones during stimulation.

Transmitter release from bipolar cells in the retina is regulated by a variety of light-evoked voltage changes from transient $\mathrm{Ca}^{2+}$ spikes (Protti et al., 2000) to sustained depolarization (Kaneko, 1970). The fast component of transmitter release may transmit rapid changes in light intensity, whereas the slow component may be used to convey gradual changes. Thus, the activation of PKC may emphasize the information with low frequency. Filtering properties of retinal ganglion cells (Keat et al., 2001) are not static but subject to visual environments, such as temporal changes in contrast (Rieke, 2001). Filtering properties of ganglion cells should be affected by the kinetics of transmitter release from bipolar cells. As demonstrated in the present study, the kinetics of transmitter release is actually modified by the activation of PKC at bipolar terminals. It seems likely that PKC of bipolar cells may be activated by transmitters released from amacrine cells.

\section{REFERENCES}

Asaoka Y, Nakamura S, Yoshida K, Nishizuka Y (1992) Protein kinase $\mathrm{C}$, calcium and phospholipid degradation. Trends Biochem Sci 17:414-417.

Betz A, Ashery U, Rickmann M, Augustin I, Neher E, Südhof TC, Rettig J, Brose N (1998) Munc13-1 is a presynaptic phorbol ester receptor that enhances neurotransmitter release. Neuron 21:123-136.

Bowlby MR, Levitan IB (1995) Block of cloned voltage-gated potassium channels by the second messenger diacylglycerol independent of protein kinase C. J Neurophysiol 73:2221-2229.

Brose N, Rosenmund C, Rettig J (2000) Regulation of transmitter release by Unc-13 and its homologues. Curr Opin Neurobiol 10:303-311.

Castagna M, Takai Y, Kaibuchi K, Sano K, Kikkawa U, Nishizuka Y (1982) Direct activation of calcium-activated, phospholipid-dependent protein kinase by tumor-promoting phorbol esters. J Biol Chem 257:7847-7851.

Cochilla AJ, Angleson JK, Betz WJ (2000) Differential regulation of granule-to-granule and granule-to-plasma membrane fusion during secretion from rat pituitary lactotrophs. J Cell Biol 150:839-848.

Cremona O, De Camilli P (1997) Synaptic vesicle endocytosis. Curr Opin Neurobiol 7:323-330.

Debanne D, Guérineau NC, Gähwiler BH, Thompson SM (1996) Paired-pulse facilitation and depression at unitary synapses in rat hippocampus: quantal fluctuation affects subsequent release. J Physiol (Lond) 491:163-176.

Dodge Jr FA, Rahamimoff R (1967) Co-operative action a calcium ions in transmitter release at the neuromuscular junction. J Physiol (Lond) 193:419-432.

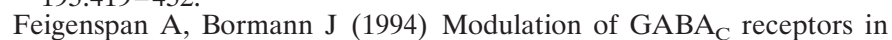
rat retinal bipolar cells by protein kinase C. J Physiol (Lond) 481:325-330.

Gillette MA, Dacheux RF (1996) Protein kinase modulation of GABA currents in rabbit retinal rod bipolar cells. J Neurophysiol 76:30703086.

Gillis KD (1995) Techniques for membrane capacitance measurements. In: Single-channel recordings, Ed 2 (Sakmann B, Neher E, eds), pp 155-198. New York: Plenum.

Gillis KD, Mößner R, Neher E (1996) Protein kinase C enhances exocytosis from chromaffin cells by increasing the size of the readily releasable pool of secretory granules. Neuron 16:1209-1220.

Hilfiker S, Augustine GJ (1999) Regulation of synaptic vesicle fusion by protein kinase C. J Physiol (Lond) 515:1.

Hoffman DA, Johnston D (1998) Downregulation of transient K ${ }^{+}$channels in dendrites of hippocampal CA1 pyramidal neurons by activation of PKA and PKC. J Neurosci 18:3521-3528.
Hori T, Takai Y, Takahashi T (1999) Presynaptic mechanism for phorbol ester-induced synaptic potentiation. J Neurosci 19:7262-7267.

Job C, Lagnado L (1998) Calcium and protein kinase C regulate the actin cytoskeleton in the synaptic terminal of retinal bipolar cells. J Cell Biol 143:1661-1672.

Kamiya H, Zucker RS (1994) Residual $\mathrm{Ca}^{2+}$ and short-term synaptic plasticity. Nature 371:603-606.

Kaneko A (1970) Physiological and morphological identification of horizontal, bipolar and amacrine cells in goldfish retina. J Physiol (Lond) 207:623-633.

Kaneko A, Tachibana M (1985) A voltage-clamp analysis of membrane currents in solitary bipolar cells dissociated from Carassius auratus. J Physiol (Lond) 358:131-152.

Keat J, Reinagel P, Reid RC, Meister M (2001) Predicting every spike: a model for the responses of visual neurons. Neuron 30:803-817.

Kobayashi K, Tachibana M (1995) $\mathrm{Ca}^{2+}$ regulation in the presynaptic terminals of goldfish retinal bipolar cells. J Physiol (Lond) 483:79-94.

Llinás R, Steinberg IZ, Walton K (1981) Relationship between presynaptic calcium current and postsynaptic potential in squid giant synapse. Biophys J 33:323-351.

McCord R, Klein A, Osborne NN (1996) The occurrence of protein kinase $\mathrm{C} \theta$ and $\lambda$ isoforms in retina of different species. Neurochem Res 21:259-266.

Mennerick S, Matthews G (1996) Ultrafast exocytosis elicited by calcium current in synaptic terminals of retinal bipolar neurons. Neuron $17: 1241-1249$.

Minami N, Berglund K, Sakaba T, Kohmoto H, Tachibana M (1998) Potentiation of transmitter release by protein kinase $\mathrm{C}$ in goldfish retinal bipolar cells. J Physiol (Lond) 512:219-225.

Negishi K, Kato S, Teranishi T (1988) Dopamine cells and rod bipolar cells contain protein kinase C-like immunoreactivity in some vertebrate retinas. Neurosci Lett 94:247-252.

Okada T, Horiguchi H, Tachibana M (1995) $\mathrm{Ca}^{2+}$-dependent $\mathrm{Cl}^{-}$current at the presynaptic terminals of goldfish retinal bipolar cells. Neurosci Res 23:297-303.

Oleskevich S, Walmsley B (2000) Phosphorylation regulates spontaneous and evoked transmitter release at a giant terminal in the rat auditory brainstem. J Physiol (Lond) 526:349-357.

Osborne NN, Broyden NJ, Barnett NL, Morris NJ (1991) Protein kinase $\mathrm{C}(\alpha$ and $\beta)$ immunoreactivity in rabbit and rat retina: effect of phorbol esters and transmitter agonists on immunoreactivity and the translocation of the enzyme from cytosolic to membrane compartments. J Neurochem 57:594-604.

Osborne NN, Wood J, Groome N (1994) The occurrence of three calcium-independent protein kinase $C$ subspecies $(\delta, \epsilon$ and $\zeta)$ in retina of different species. Brain Res 637:156-162.

Protti DA, Flores-Herr N, von Gersdorff H (2000) Light evokes $\mathrm{Ca}^{2+}$ spikes in the axon terminal of a retinal bipolar cell. Neuron 25:215-227.

Rieke F (2001) Temporal contrast adaptation in salamander bipolar cells. J Neurosci 21:9445-9454.

Saitoh N, Hori T, Takahashi T (2001) Activation of the epsilon isoform of protein kinase $\mathrm{C}$ in the mammalian nerve terminal. Proc Natl Acad Sci USA 98:14017-14021.

Sakaba T, Neher E (2001) Calmodulin mediates rapid recruitment of fast-releasing synaptic vesicles at a calyx-type synapse. Neuron 32:1119-1131.

Sakaba T, Ishikane H, Tachibana M (1997a) $\mathrm{Ca}^{2+}$-activated K ${ }^{+}$current at presynaptic terminals of goldfish retinal bipolar cells. Neurosci Res 27:219-228.

Sakaba T, Tachibana M, Matsui K, Minami N (1997b) Two components of transmitter release in retinal bipolar cells: exocytosis and mobilization of synaptic vesicles. Neurosci Res 27:357-370.

Slepnev VI, Ochoa GC, Butler MH, Grabs D, De Camilli P (1998) Role of phosphorylation in regulation of the assembly of endocytic coat complexes. Science 281:821-824.

Stea A, Soong TW, Snutch TP (1995) Determinants of PKC-dependent modulation of a family of neuronal calcium channels. Neuron 15:929-940.

Suzuki S, Kaneko A (1990) Identification of bipolar cell subtypes by protein kinase $\mathrm{C}$-like immunoreactivity in the goldfish retina. Vis Neurosci 5:223-230.

Suzuki S, Tachibana M, Kaneko A (1990) Effects of glycine and GABA on isolated bipolar cells of the mouse retina. J Physiol (Lond) 421:645-662.

Tachibana M (1999) Regulation of transmitter release from retinal bipolar cells. Prog Biophys Mol Biol 72:109-133.

Tachibana M, Okada T (1991) Release of endogenous excitatory amino acids from ON-type bipolar cells isolated from the goldfish retina. J Neurosci 11:2199-2208.

Tachibana M, Okada T, Arimura T, Kobayashi K, Piccolino M (1993) Dihydropyridine-sensitive calcium current mediates neurotransmitter release from bipolar cells of the goldfish retina. J Neurosci 13:28982909. 
Toullec D, Pianetti P, Coste H, Bellevergue P, Grand-Perret T, Ajakane M, Baudet V, Boissin P, Boursier E, Loriolle F, Duhamel L, Charon D, Kirilovsky J (1991) The bisindolylmaleimide GF 109203X is a potent and selective inhibitor of protein kinase C. J Biol Chem 266:1577115781.

von Gersdorff H, Matthews G (1994) Dynamics of synaptic vesicle fusion and membrane retrieval in synaptic terminals. Nature 367:735-739. von Gersdorff H, Matthews G (1997) Depletion and replenishment of vesicle pools at a ribbon-type synaptic terminal. J Neurosci 17:19191927.

von Gersdorff H, Matthews G (1999) Electrophysiology of synaptic vesicle cycling. Annu Rev Physiol 61:725-752.

von Gersdorff H, Vardi E, Matthews G, Sterling P (1996) Evidence that vesicles on the synaptic ribbon of retinal bipolar neurons can be rapidly released. Neuron 16:1221-1227.

von Gersdorff H, Sakaba T, Berglund K, Tachibana M (1998) Submillisecond kinetics of glutamate release from a sensory synapse. Neuron 21:1177-1188.

Wu XS, Wu LG (2001) Protein kinase C increases the apparent affinity of the release machinery to $\mathrm{Ca}^{2+}$ by enhancing the release machinery downstream of the $\mathrm{Ca}^{2+}$ sensor. J Neurosci 21:7928-7936.

Yawo $H$ (1999) Two components of transmitter release from the chick ciliary presynaptic terminal and their regulation by protein kinase $\mathrm{C}$ J Physiol (Lond) 516:461-470.

Zenisek D, Steyer JA, Almers W (2000) Transport, capture and exocytosis of single synaptic vesicles at active zones. Nature 406:849-854. 